\title{
Health status decline in a-1 antitrypsin deficiency: a feasible outcome for disease modifying therapies?
}

\author{
Robert A. Stockley ${ }^{1 *}$, Ross G. Edgar ${ }^{2,3}$ (D), Sian Starkey ${ }^{4}$ and Alice M. Turner ${ }^{3,5}$
}

\begin{abstract}
Background: Trials of disease modifying therapies in Chronic Obstructive Pulmonary Disease (COPD) provide challenges for detecting physiological and patient centred outcomes. The purpose of the current study was to monitor decline in health status in Alpha-1 antitrypsin deficiency (AATD) and determine its' relationship to conventional physiology.
\end{abstract}

Methods: Patients recruited to the UK-AATD database with a median follow up of 7 years (IQR 5-10) were studied to determine annual change in St George's Respiratory Questionnaire (SGRQ), FEV ${ }_{1}$, gas transfer and their feasibility of use in future trials.

Results: Annual decline in SGRQ had a wide range, was greater for patients with established COPD and correlated with decline in $\mathrm{FEV}_{1}(p<0.0001)$. Total score decline was greater $(p<0.05)$ for those with accelerated FEV decline $_{1}$ ( median $=1.07$ points/year) compared to those without (median $=0.51$ ). Power calculations indicated effective intervention would not achieve MCID for the SGRQ unless the timeframe was extended for up to 8 years. More than 5000 patients/arm would be required for a statistically significant modest effect over 3 years even in those with rapid $\mathrm{FEV}_{1}$ decline.

Conclusion: Despite AATD being a rapidly declining form of COPD, deterioration in SGRQ was slow consistent with ageing and the chronic nature of disease progression. Power calculations indicate the numbers needed to detect a difference with disease modifying therapies would be prohibitive especially in this rare cause of COPD. These data have important implications for future study design of disease modifying therapies even in COPD not associated with AATD.

Keywords: Alpha-1 antitrypsin deficiency, Health related quality of life, Disease progression

\section{Background}

Unlike interventions that have short or medium term effects in COPD (improvement in $\mathrm{FEV}_{1}$, health status or reduction in exacerbations), therapies that modify disease progression present greater challenges to objective and subjective measures of efficacy. Physiological progression has classically been characterised by $\mathrm{FEV}_{1}$ decline although recent COPD studies indicated that not all patients decline [1] leading to attempts to identify "rapid decliners" for study enrichment by patient characteristics such as

\footnotetext{
* Correspondence: Rob.Stockley@uhb.nhs.uk

${ }^{1}$ Lung Investigation Unit, University Hospitals Birmingham NHS Foundation Trust, Queen Elizabeth Hospital Birmingham, Mindelsohn Way, Edgbaston, Birmingham B15 2GW, UK

Full list of author information is available at the end of the article
}

Emphysema [2] biomarkers such as CC16 [3] or neutrophilic proteinase footprints [4].

Health related outcomes relate to both $\mathrm{FEV}_{1}$ [5] and exacerbations [6]. A mean clinically important difference (MCID) is defined for the Saint George's Respiratory Questionnaire (SGRQ), and is a preferred secondary and co-primary outcome by the US Food and Drug Administration (FDA) recognising its clinical relevance $[7,8]$. However entry into clinical trials alone improves both compliance and health status (HS) and clinical impact has to be judged above this placebo effect.

Large COPD trials provide some evidence of disease modification (slowing $\mathrm{FEV}_{1}$ decline) in post hoc analysis of $\mathrm{TORCH}$ [9] and prospective analysis of SUMMIT 
studies [10]. However in rarer conditions predisposing to COPD, like Alpha-1 antitrypsin deficiency (AATD), where treatments such as augmentation therapy might be expected to modify disease progression, it is impractical to deliver powered studies with conventional outcomes. The number needed to determine the effect on $\mathrm{FEV}_{1}$ decline is deemed prohibitive [11] so a more direct measure of the pathology (emphysema progression) by Computed Tomography has been accepted as a surrogate outcome by the FDA [12]. Nevertheless despite consistent double blind studies of disease modification [13-15] there remains uncertainty about whether augmentation improves other outcomes, such as HS, although there is observational evidence that mortality is reduced [16].

Disease modification in COPD is becoming an important pharmaceutical objective and several anti-inflammatory and anti proteinase strategies are being developed and undergoing phase $1 / 2$ testing. The delivery of phase 3 clinical trials needs to address the use of SGRQ in trial design as outlined by the FDA $[7,8]$. The purpose of the current study was to determine whether HS defined by the SGRQ could be employed as part of future AATD trials to provide clearer evidence of patient benefit and how the decline of lung physiology influences the SGRQ decline in a cohort of closely monitored patients with AATD never treated with antitrypsin augmentation therapy.

\section{Methods}

The UK AATD registry collects extensive annual demographic data including post bronchodilator lung function (to ERS /ARTP standard) and SGRQ as described [17]. All PiZZ patients $(n=454)$ where SGRQ was available for at least 4 consecutive annual visits, were analysed. The decline in SGRQ total score and the domains were assessed by linear regression analysis to determine change/year. Data was compared between GOLD stages [18] and subgroups defined as non and rapid decliners ( $\geq 1 \%$ predicted decline per year) for $\mathrm{FEV}_{1}$ and Kco as described previously [19]. Lung function was normalised for age, sex, height and ethnicity using the normal ranges described [20]. All patients gave written consent and the study had ethical approval (South Birmingham LREC 3359a).

\section{Statistical analysis}

Statistical analysis used STATA 14 (StataCorp LLC, Texas, USA). A significance level of $p<0.05$ was used with single tailed tests. Data was not normally distributed, hence is expressed as median and interquartile range. Correlations between baseline and longitudinal SGRQ and pulmonary physiology were determined by linear mixed modelling and differences between groups assessed by Mann-Whitney two sample statistic (two independent variables) and Kruskal Wallis (group wise comparisons). Missing data underwent a case deletion if greater than $5 \%$.

Sample size calculations for a study with SGRQ as the primary outcome together with potential physiological outcomes were based upon a two group parallel comparison, using the formula $n=1+2 C(\mathrm{~S} / \mathrm{D}) 2$ where $\boldsymbol{D}$ was the smallest difference to be detected (a 25\% change in SGRQ decline was used as an arbitrary effect size for illustrative purposes) and $s$ represented the standard deviation of the observations. $\boldsymbol{C}=10.51$ to provide a $90 \%$ power of detecting a change in SGRQ at the 5\% level of significance. As the deterioration in HS was determined by slope analysis over at least 4 annual assessments, power would be relevant for a 3 year study.

\section{Results}

\section{Patient cohort}

Data was collected from 454 patients with AATD (PiZZ) with median follow up of 7 years (IQR 5-10). Demographics of patients with and without airflow obstruction $\left(\mathrm{FEV}_{1}\right.$ /FVC ratio greater or less than 0.7) [18] are shown in Table 1 . The majority with airflow obstruction were male (64\%) and $89 \%$ were index cases diagnosed due to respiratory symptoms. The majority were ex smokers (81\%):- no current smokers were included in the analysis as there were too few to analyse meaningfully. Patients without COPD were mainly female (61\%), non index cases, never smokers and younger (Table 1). There was a wide range of pulmonary function from normal to very severe COPD (GOLD stage 4) also reflected in the gas transfer results and SGRQ scores for the groups with and without COPD.

Relationship between SGRQ and physiological parameters The baseline SGRQ score for the whole group showed a statistically significant $(p<0.0001)$ correlation with baseline $\mathrm{FEV}_{1}$ although the $\mathrm{r}^{2}$ value of 0.34 indicated that only $34 \%$ of the variability in the group was explained by $\mathrm{FEV}_{1}$ alone (Fig. 1). The correlations for those with and without COPD were also statistically significant $(p<0.0001)$ although the variance for each group was less $\left(r^{2}=0.20\right.$ and 0.15 respectively). Similar statistically significant correlations were found between SGRQ total score and gas transfer for the whole group $\left(r^{2}=0.105 ; p<0.0001\right)$ and those with COPD $\left(r^{2}=0.015 ; p=0.008\right)$ but not those without COPD $\left(r^{2}=0.002 ; p=0.35\right)$.

There was a wide range of $\mathrm{FEV}_{1}$ and Kco decline (\% predicted/year). Generally the SGRQ scores increased yearly for the groups with and without COPD, although again a wide range was seen (Table 1). The symptom and activity score was stable for the non COPD group even though the median total score showed gradual deterioration (+ 0.21 units /year). The group with COPD 
Table 1 Patient characteristics

\begin{tabular}{|c|c|c|c|c|c|c|c|}
\hline & \multicolumn{3}{|c|}{ No Obstruction } & \multicolumn{3}{|c|}{ Obstruction } & \multirow[t]{2}{*}{$p$} \\
\hline & $\mathrm{N}$ & Median & IQR & $\mathrm{N}$ & Median & $\mathrm{IQR}$ & \\
\hline Male $\mathrm{n}(\%)$ & \multicolumn{3}{|c|}{$33(39 \%)$} & \multicolumn{3}{|c|}{$235(64 \%)$} & $<0.001$ \\
\hline Age & 84 & 42.4 & $35.5-53.9$ & 370 & 52.5 & $46.4-58.5$ & $<0.001$ \\
\hline Index n(\%) & \multicolumn{3}{|c|}{$39(46 \%)$} & \multicolumn{3}{|c|}{331 (89\%) } & $<0.001$ \\
\hline Never Smoker n(\%) & \multicolumn{3}{|c|}{$59(70 \%)$} & \multicolumn{3}{|c|}{72 (19\%) } & $<0.001$ \\
\hline Pack Year History & 25 & 6.0 & $2.0-12.8$ & 296 & 19.0 & $10.0-28.0$ & $<0.001$ \\
\hline $\mathrm{BMI}$ & 84 & 25.9 & $23.1-29.9$ & 370 & 25.1 & $22.8-27.9$ & 0.043 \\
\hline \multicolumn{8}{|l|}{ Baseline } \\
\hline $\mathrm{FEV}_{1} \%$ predicted & 84 & 113.8 & $97.9-123.0$ & 370 & 49.2 & $36.5-66.1$ & $<0.001$ \\
\hline FVC $\%$ predicted & 84 & 115.0 & $102.2-129.0$ & 370 & 108.3 & $94.8-124.3$ & 0.025 \\
\hline $\mathrm{FEV}_{1} /$ FVC Ratio & 84 & 80.6 & $77.2-86.0$ & 370 & 37.6 & $30.3-48.0$ & $<0.001$ \\
\hline TLCO \% predicted & 84 & 92.5 & $80.8-108.9$ & 368 & 66.2 & $52.5-77.1$ & $<0.001$ \\
\hline Kco \% predicted & 84 & 91.1 & $79.3-100.3$ & 368 & 63.6 & $52.1-74.3$ & $<0.001$ \\
\hline SGRQ Symptoms & 84 & 30.9 & $11.7-57.1$ & 370 & 62.5 & $46.2-78.6$ & $<0.001$ \\
\hline SGRQ Activity & 84 & 12.2 & $0-41.6$ & 370 & 60.4 & 47.4-79.7 & $<0.001$ \\
\hline SGRQ Impacts & 84 & 5.8 & $0-21.4$ & 370 & 34.9 & $21.3-49.9$ & $<0.001$ \\
\hline SGRQ Total & 84 & 14.0 & $4.8-35.5$ & 370 & 48.2 & $33.9-62.4$ & $<0.001$ \\
\hline \multicolumn{8}{|l|}{ Annual Decline } \\
\hline $\mathrm{FEV}_{1} \%$ predicted Slope/yr & 84 & -0.25 & $-1.11-0.47$ & 370 & -1.02 & $-1.99--0.03$ & $<0.001$ \\
\hline Kco \% predicted Slope/yr & 84 & -0.92 & $-1.66-0.01$ & 364 & -1.13 & $-1.94--0.42$ & 0.063 \\
\hline SGRQ Symptoms Slope/yr & 84 & 0.00 & $-2.45-2.02$ & 370 & 0.21 & $-2.29-2.15$ & 0.291 \\
\hline SGRQ Activity Slope/yr & 84 & 0.00 & $-0.78-1.37$ & 370 & 1.18 & $-0.47-3.62$ & $<0.001$ \\
\hline SGRQ Impacts Slope/yr & 84 & 0.14 & $-0.53-0.94$ & 370 & 0.38 & $-1.07-2.18$ & 0.092 \\
\hline SGRQ Total Slope/yr & 84 & 0.21 & $-0.76-1.06$ & 370 & 0.66 & $-0.83-2.37$ & 0.025 \\
\hline
\end{tabular}

Demographics of the patient group divided into those with and without airflow obstruction (FEV $1 / F V C$ ratio above and below 0.7$)$. Data is expressed as median and interquartile range. The annual \% predicted decline in lung function and St George's Respiratory Questionnaire domains are also shown

$B M I$ Body mass index, FEV 1 Forced Expiratory Volume in 1 Second, FVC Forced Vital Capacity, TLCo Diffusing Capacity of the Lung for carbon monoxide, Kco Transfer Coefficient for carbon monoxide, SGRQ St George's Respiratory Questionnaire

showed a worsening of symptoms and activity with time and an overall median increase in total score of + 0.66 units/year although only the activity and total score deteriorated more rapidly than for those without COPD $(p=0.001$ and $p=0.025$ respectively). Figure 2 shows the annual change in SGRQ and its domains in patients with and without COPD, divided according to no or rapid decline in $\mathrm{FEV}_{1}$ [19]. Summary data and demographics of patients in each of these groups is provided in Additional file 1: Tables $S 1$ and S2. In addition the $\mathrm{FEV}_{1}$ and Kco decline is summarised in Additional file 1: Tables S3a, $\mathrm{b}$ and $\mathrm{c}$ for comparison with previous literature that did not account for age sex and height.

There was no difference in the rate of gas transfer decline between those with and without COPD $(p=0.125)$. There was no relationship between SGRQ decline and gas transfer decline (Additional file 1: Tables S4 and S5). The decline in $\mathrm{FEV}_{1}$ was statistically related to the increase in SGRQ total score for the whole group (Fig. 3; $p<0.0001$ ), although the relationship $\left(\mathrm{r}^{2} 0.04\right)$ indicated only $4 \%$ of the decline in $\mathrm{HS}$ was explained by the decline in $\mathrm{FEV}_{1}$ alone. The decline in HS was greater in COPD patient with rapid decline in $\mathrm{FEV}_{1}$ (\%predicted) compared to those with no decline although only for the total score and activity domain $(p<0.05)$ as shown in supplementary e-Table 2.

The decline in SGRQ total score did not differ between GOLD stages (Fig. 4).

\section{Relationship between change in SGRQ and COPD treatment}

Forty eight $\%$ of patients without COPD and $2 \%$ of those with COPD were not receiving long acting inhaled therapy. The proportion receiving LABA, LAMA or ICS alone were similar for those without and those with COPD $(11 \%$ vs $19 \%$ : $9 \%$ vs $9 \%$ : and $4 \%$ vs $7 \%$ respectively). However, only 9\% of those without COPD were on triple therapy (LAMA/LABA/ICS) compared to $61 \%$ of those with COPD. The high proportion of those without spirometric COPD at the time of referral who were on regular inhaled therapy largely reflects clinical practice at the time of 


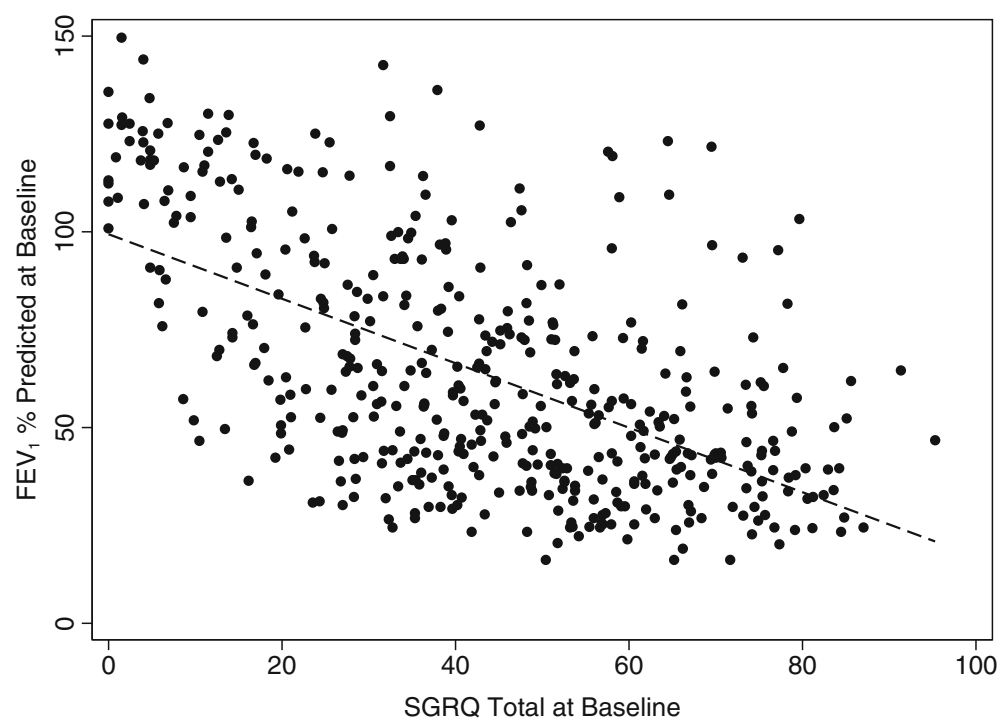

Fig. 1 Correlation between $\mathrm{FEV}_{1}$ (\% predicted) and SGRQ total score at baseline. Each point represents a single patient. The dashed line is a linear regression. $P<0.0001 R^{2}=0.344$

referral and symptoms related to discordance beteen spirometry and gas transfer as described previously [21]. There was no relationship between the decline in HS and the nature of regular inhaled therapy assessed as categorical data.

\section{Power calculations}

Table 2 summarises the numbers needed to confirm a $25 \%$ difference in decline in SGRQ total score or $\mathrm{FEV}_{1}$ for the group with COPD, and for those with rapid decline in $\mathrm{FEV}_{1}$, assuming $90 \%$ power and with a type 1 error set at 5\%, The numbers required to detect a $25 \%$ difference in Kco decline, in those with COPD and rapid decline is also shown.

\section{Discussion}

The SGRQ is a validated, but subjective, measure of a patient's HS. The current study provides unique and

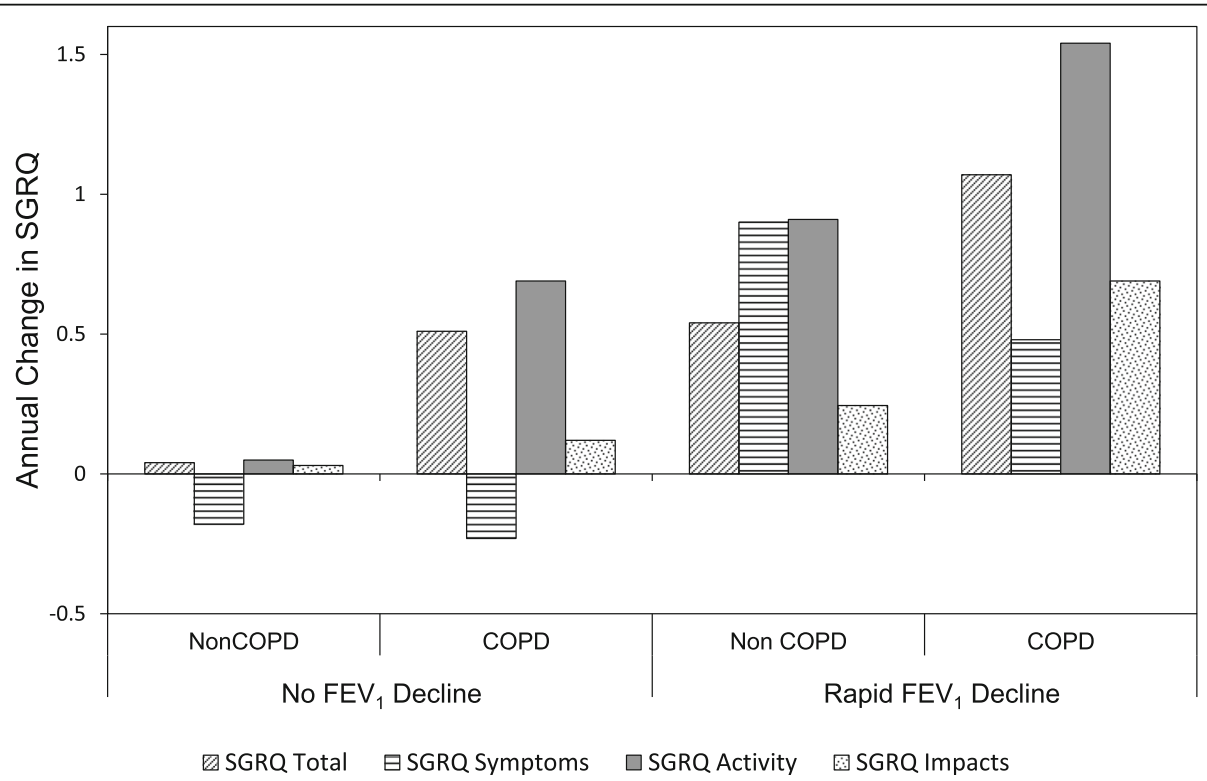

Fig. 2 Annual decline in SGRQ total score and its domains. The histograms indicate median values in patients with and without COPD and rapid $\mathrm{FEV}_{1}$ decline. Note even those with COPD and rapid $\mathrm{FEV}_{1}$ decline have a median total score deterioration well below the MCID 


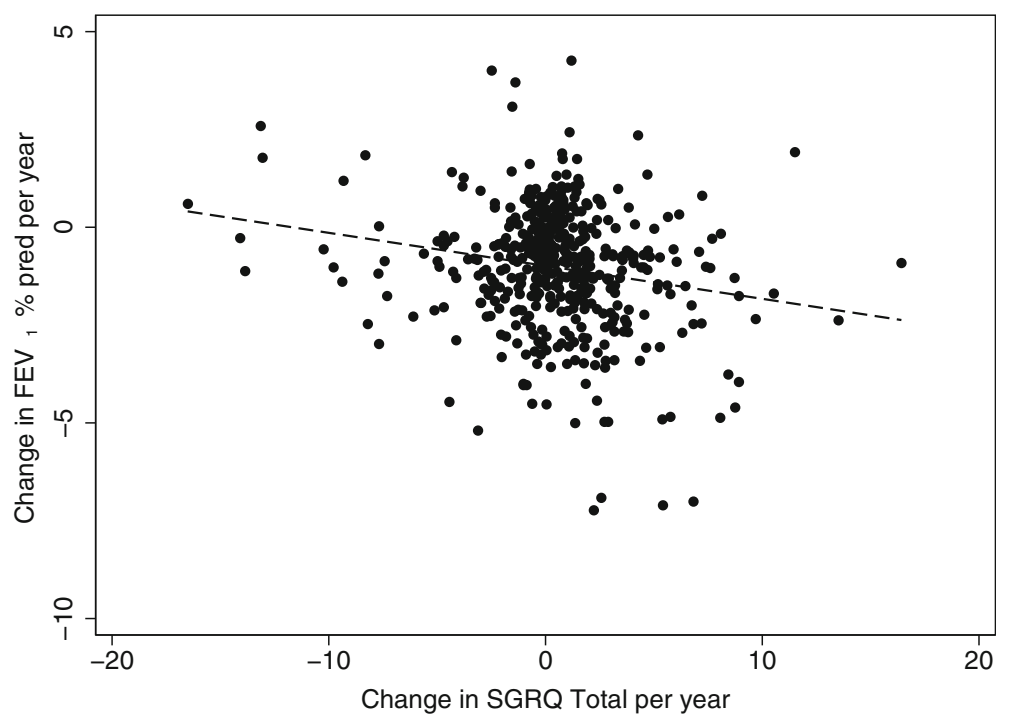

Fig. 3 Relationship between deterioration in $\mathrm{FEV}_{1}$ and $\mathrm{SGRQ}$. The decline in $\mathrm{FEV}_{1}$ is shown compared to the annual change in SGRQ total score. Each point represents data from a single patient. The dashed line is a linear regression, $r^{2}=0.04, p<0.001$

critical data on the effect of AATD on annual HS deterioration over a period of 3 or more years in patients not receiving augmentation therapy, thus reflecting the natural history of the disease. It demonstrates that change in HS relates poorly to physiological progression and that it would not be feasible to establish a trial of disease modifying therapy with SGRQ as a primary outcome. In addition SGRQ is unlikely to provide direct clinical support as a secondary outcome because the numbers required, especially in this rare disease, are prohibitive.

\section{Patterns of change in health status}

Patients were divided into those with and without airflow obstruction and all SGRQ domains and total score showed a wide range of values though significantly worse for those with COPD. However, even in those without COPD the total score and especially the symptom domain score was

Table 2 Numbers required to power an augmentation trial

\begin{tabular}{lll}
\hline Parameter & & $\begin{array}{l}\text { No. needed per arm to detect } \\
25 \% \text { reduction in decline }\end{array}$ \\
\hline SGRQ total score & Whole group & 8577 \\
& Rapid $\mathrm{FEV}_{1}$ decliners & 5039 \\
FEV $_{1}$ (\% predicted) & Whole group & 1516 \\
& Rapid FEV , decliners $^{2}$ & 86 \\
Kco (\% predicted) & Whole group & 569 \\
& Rapid Kco decliners & 77 \\
\hline
\end{tabular}

The number that is required in each arm with total SGRQ score or lung function as the outcome based on patients with a diagnosis of COPD or only those with known rapid decline in physiology as indicated

FEV 1 Forced Expiratory Volume in 1 Second, Kco Transfer Coefficient for carbon monoxide, SGRQ St George's Respiratory Questionnaire higher than expected in a healthy population [22]. This likely reflects the proportion of patients in our study who were "index" cases and hence diagnosed after presenting with symptoms. Whereas these patients did not have COPD by spirometric criteria we have shown previously that in AATD the gas transfer can be reduced even in subjects with normal spirometry and likely leads to referral and assessment [21]. This concept is consistent with the lower scores in the non index Swedish birth cohort who have been followed for up to 40 years where HS is maintained and only a small number of current smokers show HS or gas transfer impairment [23].

Changes in HS were greater in those with established COPD, especially the activity score which increased almost +1.2 units/year, whilst total score change was lower (+ 0.66/year) reflecting the lesser changes in symptom and impact domains. The relationship to GOLD stage indicated those with mild and moderate COPD had the greatest median deterioration in total SGRQ score although there was no statistical difference across groups. Our previous studies had shown little change in average SGRQ scores over 3 years [24] which was at variance with a Dutch AATD study which showed a major decline in total score (+ 6.5 units) over 30 months [25]. The difference likely reflects a combination of the centralisation of patient care and the degree of monitoring carried out at our centre as well as potential improvements in patient care over the intervening 14 years. More recently a study from Germany [26] also documented a slow decline in SGRQ in AATD (+ 1.2 units for total score) which weakly reflected annual exacerbation rates [26]. However, that data was self-reported and 


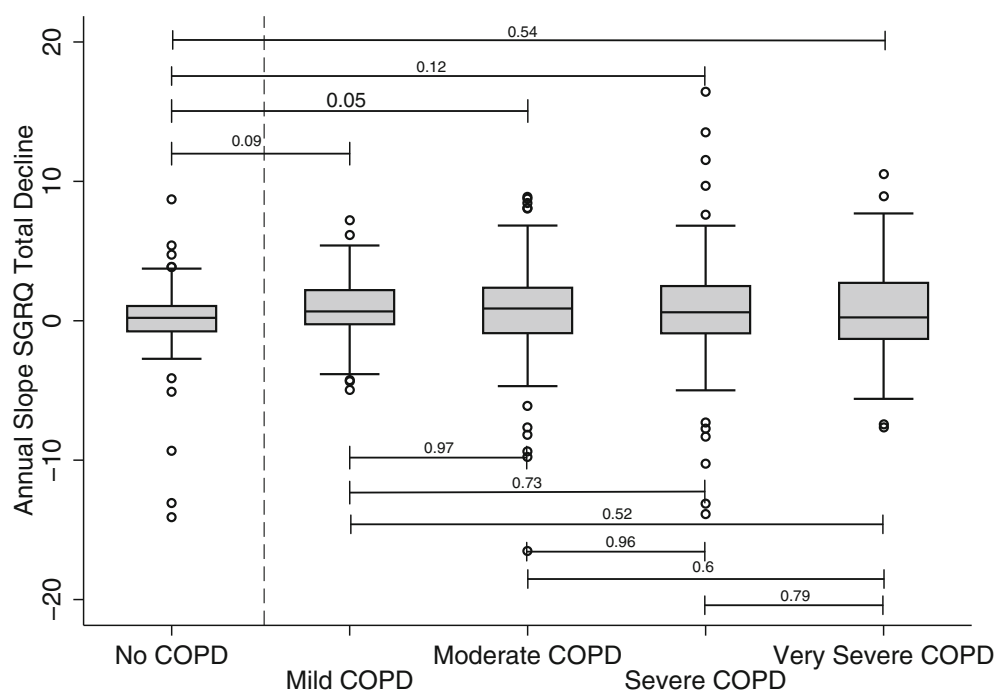

Fig. 4 Relationship between GOLD stage and change in SGRQ. The annual change in Total SGRQ is shown for the patient groups separated into the GOLD stages. The data is shown as median with IQR (box), 5-95\% range (whiskers) and outliers (open squares). The significance of the difference between groups is shown as the $p$ value on the horizontal bars

included unquantified patients with the SZ phenotype and a significant proportion on augmentation therapy, which may have influenced the results.

The SGRQ domains and total score showed little change in patients with no airflow obstruction. However there was a relationship to the $\mathrm{FEV}_{1}$ decline (\% predicted): those with rapid decline showed a greater median increase in all domains and total score although the range was wide and only significantly different for the symptom domain. There were differences in the activity domain and total scores when the COPD patients were divided into those with no or rapid decline in $\mathrm{FEV}_{1}$. However, when divided into those with rapid or no decline in gas transfer, although the activity domains rose by median values of + 0.18 and +1.17 units/year respectively, neither achieved statistical significance (Additional file 1: Tables S4 and S5) suggesting the rate of $\mathrm{FEV}_{1}$ decline has the more noticeable effect on HS. Although there was an overall (significant) correlation between $\mathrm{FEV}_{1}$ decline and SGRQ deterioration, the relationship was weak (Fig. 3).

\section{Relevance to clinical trial design}

These data have important implications for clinical trials of disease modifying therapies in AATD and non deficient COPD. Age itself (without COPD) has an effect on HS [22] although clearly from a lower baseline than in COPD. AATD is considered a more rapidly progressive type of COPD but even those with established COPD stratified for rapid $\mathrm{FEV}_{1}$ decline had an overall median annual increase in total SGRQ score that was only +0.5 points higher than those with no age corrected $\mathrm{FEV}_{1}$ decline. Indeed even when stratified into moderate and severe
COPD (typical of patients currently included in clinical trials) the differences remained small and statistically insignificant.

Our data was generated from a specialised research programme with annual follow up, which conceivably has a similar placebo effect on HS to that seen in clinical trials [27] and may reflect changes in patient expectations as well as close monitoring and better adherence to background therapy [28]. Despite similar close monitoring, many interventional trials in COPD demonstrate a greater treatment effect on HS parameters ( $\geq$ MCID of 4 points for SGRQ total score) which may reflect the nature of the trials aimed at both short term improvement in lung function and modification of exacerbations (e.g. [29, 30]). However, in trials of augmentation therapy in AATD to date no signal has been detected either statistically or close to the MCID [13-15] leading to scepticism about efficacy despite significant effects on emphysema progression [31]. This failure may reflect both the size of the studies in this rare condition and the lack of any immediate improvement in lung function (and hence a noticeable clinical signal) for disease modifying treatments like augmentation.

We observed a slow deterioration in SGRQ scores in patients not receiving augmentation therapy, indicating that detection of slowing of HS decline in clinical trials aimed at disease modification is likely to require very large numbers for adequate power. If augmentation stopped all HS decline it would still require at least a 4 year study in rapid $\mathrm{FEV}_{1}$ decliners to achieve the MCID for total SGRQ score. Our data shows that even those with stable $\mathrm{FEV}_{1}$ have an annual deterioration in 
$\mathrm{HS}$ which is half that of the rapid $\mathrm{FEV}_{1}$ decliners indicating that a study to find a median 4 point effect of treatment that stopped the physiological related decline would take about 8 years.

In the current study we calculated the number needed to confirm a $25 \%$ reduction in SGRQ total score decline which, even in pre-identified rapid decliners with COPD (5039 / arm) is prohibitive for a "rare" disease, especially when most identified patients are already on widely accepted AAT augmentation therapy. To detect an SGRQ decline reduced to that seen in COPD patients with a stable age related decline (50\% reduction) would still require 1260/arm if treatment were totally effective. Using slope analysis allows projections of the longer term benefit on HS decline, but would still require at least 3 years for decline to be documented and would still not reduce patients required in such a trial to a feasible number.

Slope analysis of health status was preferred to endpoint analysis to overcome any potential regression to the mean resulting in an apparent improvement in scores overtime [32] and at the same time allow more robust longitudinal projection of the changes to determine time to MCID.

Since SGRQ appeared prohibitive as a primary or secondary outcome we also conducted power calculations for a prospective study using both $\mathrm{FEV}_{1}$ and Kco as the outcome. Again the numbers appear prohibitive for unselected patients with AATD and COPD. However, the numbers become more feasible if patients were chosen by known rate of rapid physiological decline (Table 2) i.e. enriching the study population for the outcome being assessed. This approach could be considered for both a pragmatic clinical trial and, in the interim, as a criterion for assessing treatment response [19]. Interestingly the power calculations form a rank order consistent with previously published data on the sensitivity of these 3 parameters to change [33].

\section{Potential strengths and weaknesses}

The current study has a potential weakness. It represents a cohort of patients referred to a specialist centre for annual long term follow up as a research programme. Thus it will not represent "usual" clinical care and a degree of selection bias cannot be discounted. However, this is also a strength as the patients and their management likely represent those who would be suitable for, and included in, clinical trials. The results therefore represent what impact a focussed clinical service has on $\mathrm{HS}$ and its deterioration and are therefore relevant to the design of trials of disease modifying therapies in AATD where placebo arms should achieve similar results. Equivalent data will also be important in non AATD COPD as use of disease modifying therapies expand to this patient group.
As we were studying HS decline we only included patients in whom this had been documented on at least 4 annual visits. Some patients may not have had this recorded and some may not have returned on at least 4 occasions either because they had become reassured of their physiological "normality" of a combination of distance travelled with and without increased morbidity with time. Nevertheless this selections criterion did not differ with disease severity suggesting it is generally reflective of the patient groups.

The insensitivities of both group physiological data and HS, to change [33] has been an important driving force in the development and validation of CT densitometry as the outcome of choice in emphysema trials especially in AATD. Although lung densitometry relates to both FEV1 and SGRQ cross-sectionally and remains the best predictor of Mortality [34] only the decline in FEV1 has been shown to relate to the decline in lung Density [35]. Whether density decline shows a similar relationship to SGRQ deterioration has not been assessed but such studies may provide indirect evidence of any putative, clinically apparent, benefit that would not be detected by current trial design and power.

\section{Conclusion}

Although HS relates to baseline lung physiology and its decline, the changes are minimal with time even in those with documented rapid physiological decline. These data support the role of close patient supervision and monitoring in a specialist clinic and provides fuel for debate about trial designs to assess therapeutic efficacy of COPD disease modification with HS as an outcome.

\section{Additional file}

Additional file 1: Table S1. Demographics of patients without COPD. Table S2. Demographics of patients with COPD. Tables S3. a-c FEV1 and Kco decline including annual change in absolute units. Table S4. SGRQ domains and total scores for non COPD cohort split by those with normal age related decline in Kco and those with rapid decline. Table S5. SGRQ deterioration for COPD cohort split by normal age related Kco decline and rapid Kco decline. (DOCX $35 \mathrm{~kb}$ )

\footnotetext{
Abbreviations

AAT: Alpha-1 Antitrypsin; AATD: Alpha-1 Antitrypsin Deficiency; ARTP: Association for Respiratory Technology and Physiology; BMl: Body Mass Index; COPD: Chronic Obstructive Pulmonary Disease; ERS: European

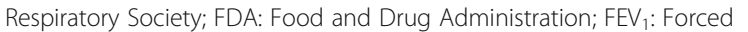
Expiratory Volume in 1 Second; FEV 1 /FVC: The Ratio of FEV 1 and FVC; FVC: Forced Vital Capacity; GOLD: Global Initiative for Chronic Obstructive Lung Disease; HS: Health Status; ICS: Inhaled corticosteroid; IQR: Interquartile Range; Kco: Transfer Coefficient for carbon monoxide; LABA: Long acting Beta 2 antagonist; LAMA: Long acting muscarinic antagonist; LREC: Local Research Ethics Committee; MCID: Minimum Clinical Important Difference; n: Number; NIHR: National Institute for Health Research; PkYrHx: Pack Year History; QoL: Quality of Life; SGRQ: St George's Respiratory Questionnaire; TLCo: Diffusing Capacity of the Lung for carbon monoxide; UK: United Kingdom
} 


\section{Funding}

The registry programme was funded by non-commercial grants from CSL Behring, Bayer biologicals, Talecris and Grifols as well as the Alpha-1Foundation, West Midlands Chest Fund and the National Institute for Health Research.

\section{Availability of data and materials}

The datasets generated and/or analysed during the current study are not publicly available due to ongoing clinical trial but may be available from the corresponding author on reasonable request.

\section{Authors' contributions}

RAS, RGE, SH and AMT contributed substantially to the study design, data analysis interpretation, and writing of the manuscript. All authors read and approved the final manuscript.

\section{Ethics approval and consent to participate}

All patients gave written informed consent in line with GCP and the study had ethical approval from South Birmingham LREC 3359a.

\section{Consent for publication}

Not applicable.

\section{Competing interests}

RAS had full access to all of the data in the study and takes responsibility for the integrity of the data and the accuracy of the data analysis.

RAS has received fees for advisory board activity from CSL Behring, Shire pharmaceuticals, Kamada, Boehringer Ingelheim, Akari, Mereobiopharma and Astra Zeneca.

RGE reports grants from Health Education England (HEE) and National Institute for Health Research (NIHR) (CDRF-2014-05-044), during the conduct of the study. This article presents independent research funded by the NIHR. The views expressed are those of the authors and not necessarily those of the NHS, the NIHR or the Department of Health.

$\mathrm{SH}$ declares that she has no competing interests.

AMT reports grants from Grifols biotherapeutics, and from Alpha-1 Foundation, outside the submitted work.

\section{Publisher's Note}

Springer Nature remains neutral with regard to jurisdictional claims in published maps and institutional affiliations.

\section{Author details \\ ${ }^{1}$ Lung Investigation Unit, University Hospitals Birmingham NHS Foundation Trust, Queen Elizabeth Hospital Birmingham, Mindelsohn Way, Edgbaston, Birmingham B15 2GW, UK. ${ }^{2}$ Therapy Services, University Hospitals Birmingham NHS Foundation Trust Queen Elizabeth Hospital Birmingham, Mindelsohn Way, Edgbaston, Birmingham B15 2GW, UK. ${ }^{3}$ Institute of Applied Health Research, University of Birmingham, Birmingham B15 2TT, UK. ${ }^{4}$ Institute of Translational Medicine, University Hospitals Birmingham NHS Foundation Trust Queen Elizabeth Hospital Birmingham, Mindelsohn Way, Edgbaston, Birmingham B15 2GW, UK. ${ }^{5}$ Heart of England NHS Foundation Trust, Respiratory Medicine, Bordesley Green East, Birmingham B9 5SS, UK.}

\section{Received: 17 May 2018 Accepted: 13 July 2018}

Published online: 20 July 2018

\section{References}

1. Vestbo J, Edwards LD, Scanlon PD, Yates JC, Agusti A, et al. Changes in forced expiratory volume in 1 second over time in COPD. N Engl J Med. 2011;365(13):1184-92.

2. Nishimura M, Makita H, Nagai $K$, Konno S, Nasuhara $Y$, et al. Annual change in pulmonary function and clinical phenotype in chronic obstructive pulmonary disease. Am J Respir Crit Care Med. 2012;185(1):44-52.

3. Park HY, Churg A, Wright JL, Li Y, Tam S, et al. Club cell protein 16 and disease progression in chronic obstructive pulmonary disease. Am J Respir Crit Care Med. 2013:188(12):1413-9.

4. Carter R, Mumford R, Treonze K, Stockley R. Fibrinopeptide AA-VAL360: a footprint of neutrophil elastase activity. COPD: J Chron Obstruct Pulmon Dis. 2011;8(1):50-1.

5. Dowson LJ, Guest PJ, Hill SL, Holder RL, Stockley RA. High-resolution computed tomography scanning in alpha1-antitrypsin deficiency: relationship to lung function and health status. Eur Respir J. 2001;17(6): 1097-104.

6. Seemungal TA, Donaldson GC, Paul EA, Bestall JC, Jeffries DJ, et al. Effect of exacerbation on quality of life in patients with chronic obstructive pulmonary disease. Am J Respir Crit Care Med. 1998;157(5):1418-22.

7. U.S. Food and Drug Administration. Chronic Obstructive Pulmonary Disease: Developing Drugs for Treatment Guidance for Industry (Draft Guidance). 2016 [Available from: http://www.fda.gov/downloads/Drugs/ GuidanceComplianceRegulatoryInformation/Guidances/UCM071575.pdf.

8. U.S. Food and Drug Administration. In: U.S. Department of Health and Human Services FaDA, Center for Drug Evaluation and Research (CDER), editor. Chronic Obstructive Pulmonary Disease: Use of the St. George's Respiratory Questionnaire as a PRO Assessment Tool Guidance for Industry; 2018.

9. Celli BR, Thomas NE, Anderson JA, Ferguson GT, Jenkins CR, et al. Effect of pharmacotherapy on rate of decline of lung function in chronic obstructive pulmonary disease: results from the TORCH study. Am J Respir Crit Care Med. 2008:178(4):332-8.

10. Vestbo J, Anderson JA, Brook RD, Calverley PM, Celli BR, et al. Fluticasone furoate and vilanterol and survival in chronic obstructive pulmonary disease with heightened cardiovascular risk (SUMMIT): a double-blind randomised controlled trial. Lancet. 2016:387(10030):1817-26.

11. Schluchter MD, Stoller JK, Barker AF, Buist AS, Crystal RG, et al. Feasibility of a clinical trial of augmentation therapy for alpha1- antitrypsin deficiency. Am J Respir Crit Care Med. 2000;161(3 I):796-801.

12. Plasma Protein Therapeutics Association. Clinical and Surrogate Endpoints for Evaluating Efficacy of Alpha 1-Proteinase Inhibitor (Human) Augmentation Therapy: FDA Blood Products Advisory Committee; 2009 [Available from: https://www.pptaglobal.org/.../954-ppta-statement-onclinical-and-surrogate-endpoints....

13. Chapman KR, Burdon JG, Piitulainen E, Sandhaus RA, Seersholm N, et al Intravenous augmentation treatment and lung density in severe alpha1 antitrypsin deficiency (RAPID): a randomised, double-blind, placebocontrolled trial. Lancet. 2015;386(9991):360-8.

14. Dirksen A, Dijkman JH, Madsen F, Stoel B, Hutchison DCS, et al. A randomized clinical trial of alpha1-antitrypsin augmentation therapy. Am J Respir Crit Care Med. 1999;160(5 I):1468-72.

15. Dirksen A, Piitulainen E, Parr DG, Deng C, Wencker M, et al. Exploring the role of $C T$ densitometry: a randomised study of augmentation therapy in alpha1-antitrypsin deficiency. Eur Respir J. 2009;33(6):1345-53.

16. The Alpha-1-Antitrypsin Deficiency Registry Study Group. Survival and FEV1 decline in individuals with severe deficiency of alpha1-antitrypsin. A J Respir Crit Care Med. 1998;158(1):49-59.

17. Dowson LJ, Newall C, Guest PJ, Hill SL, Stockley RA. Exercise capacity predicts health status in alpha1-antitrypsin deficiency. Am J Respir Crit Care Med. 2001;163(4):936-41.

18. Vogelmeier CF, Criner GJ, Martinez FJ, Anzueto A, Barnes PJ, et al. Global strategy for the diagnosis, management and prevention of chronic obstructive lung disease 2017 report. Respirology. 2017;22(3):575-601.

19. Stockley RA, Edgar RG, Pillai A, Turner AM. Individualized lung function trends in alpha-1-antitrypsin deficiency: a need for patience in order to provide patient centered management? Int J Chron Obstruct Pulmon Dis. 2016;11:1745.

20. Quanjer PH, Tammeling GJ, Cotes JE, Pedersen OF, Peslin R, et al. Lung volumes and forced ventilatory flows. Eur Respir J. 1993;6(Suppl 16):5-40.

21. Ward H, Turner AM, Stockley RA. Spirometric and gas transfer discordance in a alpha1 -antitrypsin deficiency. Patient characteristics and progression. Chest. 2014;145(6):1316-24

22. Ferrer M, Villasante C, Alonso J, Sobradillo V, Gabriel R, et al. Interpretation of quality of life scores from the St George's respiratory questionnaire. Eur Respir J. 2002;19(3):405-13.

23. Piitulainen E, Mostafavi B, Tanash HA. Health status and lung function in the swedish alpha 1-antitrypsin deficient cohort, identified by neonatal screening, at the age of 37-40 years. Int J Chron Obstruct Pulmon Dis. 2017;12:495.

24. Needham M, Stockley RA. Exacerbations in alpha1-antitrypsin deficiency. Eur Respir J. 2005;25(6):992-1000

25. Stolk J, Ng WH, Bakker ME, Reiber JHC, Rabe KF, et al. Correlation between annual change in health status and computer tomography derived lung density in subjects with alpha1-antitrypsin deficiency. Thorax. 2003;58(12): 1027-30.

26. Bernhard N, Lepper PM, Vogelmeier C, Seibert M, Wagenpfeil S, et al. Deterioration of quality of life is associated with the exacerbation frequency 
in individuals with alpha-1-antitrypsin deficiency-analysis from the german registry. Int J Chron Obstruct Pulmon Dis. 2017;12:1427.

27. Vincken W, van Noord JA, Greefhorst AP, Bantje TA, Kesten S, et al, Improved health outcomes in patients with COPD during 1 yr's treatment with tiotropium. Eur Respir J. 2002;19(2):209-16.

28. Vestbo J, Anderson JA, Calverley PM, Celli B, Ferguson GT, et al. Adherence to inhaled therapy, mortality and hospital admission in COPD. Thorax. 2009; 64(11):939-43.

29. Calverley P, Pauwels R, Vestbo J, Jones P, Pride N, et al. Combined salmeterol and fluticasone in the treatment of chronic obstructive pulmonary disease: a randomised controlled trial. Lancet. 2003;361(9356): 449-56.

30. Wilkinson TM, Donaldson GC, Hurst JR, Seemungal TA, Wedzicha JA. Early therapy improves outcomes of exacerbations of chronic obstructive pulmonary disease. Am J Respir Crit Care Med. 2004;169(12):1298-303.

31. Gøtzsche PC, Johansen HK. Intravenous alpha-1 antitrypsin augmentation therapy for treating patients with alpha-1 antitrypsin deficiency and lung disease. Cochrane Libr. 2016; https://doi.org/10.1002/14651858.CD007851.pub3.

32. Linden A. Assessing regression to the mean effects in health care initiatives. BMC Med Res Methodol. 2013;13(1):119.

33. Stolk J, Cooper BG, Stoel B, Rames A, Rutman O, et al. Retinoid treatment of emphysema in patients on the Alpha-1 international registry. The REPAIR study: study design, methodology and quality control of study assessments. Ther Adv Respir Dis. 2010;4(6):319-32.

34. Dawkins P, Wood A, Nightingale P, Stockley R. Mortality in alpha-1-antitrypsin deficiency in the United Kingdom. Respir Med. 2009;103(10):1540-7.

35. Parr DG, Stoel BC, Stolk J, Stockley RA. Validation of computed tomographic lung densitometry for monitoring emphysema in alpha1-antitrypsin deficiency. Thorax. 2006;61(6):485-90.

Ready to submit your research? Choose BMC and benefit from:

- fast, convenient online submission

- thorough peer review by experienced researchers in your field

- rapid publication on acceptance

- support for research data, including large and complex data types

- gold Open Access which fosters wider collaboration and increased citations

- maximum visibility for your research: over $100 \mathrm{M}$ website views per year

At $\mathrm{BMC}$, research is always in progress.

Learn more biomedcentral.com/submissions 